\title{
Integrating Social and Physical Perspectives of Mitigation Policy and Practice in Indonesia
}

\author{
Supriyati Andreastuti, Agus Budianto \\ and Eko Teguh Paripurno
}

\begin{abstract}
Earthquakes, tsunami, landslide and volcanic eruptions occur frequently in Indonesia. The frequency of events combined with high population and widely varied culture, differing levels of education and knowledge of natural hazards, as well as varied income, combine to give the country a high risk for natural disaster. Communication in hazard zones is affected by a number of factors such as: differing terminology and perceptions of hazards by the public, scientists, and disaster managers; how scientists and emergency managers communicate information; and how effectively the media transfers the information to the public. Communication is also complicated by culture, social factors and a wide variety of local languages. In Indonesia, disaster mitigation efforts at the national level are coordinated by National Disaster Management Agency; whereas, provincial and regional disaster agencies are responsible for managing within their domains and in most cases local authorities are responsible for specific mitigation actions, such as evacuations. Transferring hazard information is an important process in mitigation. In order to obtain efficient communication with the public, trusting relationships between scientists and communities are required. An understanding by scientists and emergency managers of local culture, local languages and people's character facilitates communication and contributes to trust. In addition, the media used for information can contribute significantly to improving communication. Hazard communication also aims to improve the capacity of communities through enhancing their knowledge and strengthening of their mitigation institutions. In hazard zones, effective mitigation requires
\end{abstract}

S. Andreastuti $(\bowtie) \cdot$ A. Budianto

Center for Volcanology and Geological Hazard

Mitigation, Jl. Diponegoro no 57, Bandung 40122, Indonesia

e-mail: s.andreastuti@yahoo.com

A. Budianto

e-mail: agusbudianto.vsi@gmail.com
E.T. Paripurno

Universitas Pembangunan Nasional 'Veteran'

Yogyakarta, Jl. SWK 104 (Lingkar Utara),

Condongcatur, Daerah Istimewa, Yogyakarta 55283,

Indonesia

e-mail: paripurno@upnyk.ac.id 
participation and community empowerment with activities before, during and after disasters. A lesson learned from numerous volcanic eruptions in Indonesia is that each volcano has a different character, based not only the physical characteristics of eruptions but also on geographic, social and cultural features. These features result in different responses of people during crises and they influence the way scientists and government agencies communicate and deal with the process of evacuation and repatriation.

\section{Keywords}

Natural hazards • Hazard communication - Information transfer • Lessons learnt $\cdot$ Community capacity

\section{Introduction}

Indonesia is located between 3 tectonic plates, Indo-Australia, Eurasia and Pacific plates. This plate tectonic configuration exposes the nation to a wide range of geological hazards, i.e. earthquakes, tsunami, landslides and volcano eruptions. According to the Indonesia National Disaster Agency (2014), there are about 200 million people at risk from earthquakes; 4 million at risk from tsunami, 200 million at risk from landslides and 5 million people at risk from volcanic eruptions. With a population of 227,641,326 (Government of Indonesia 2010) and the dense population in hazard zones, risk reduction efforts are a priority of the government.

This chapter will discuss disasters as related to volcanic eruptions. Indonesia has 127 active volcanoes (Fig. 1), 77 are classified Type A, which have experienced one or more eruptions since 1600 AD. Type A are monitoring priority volcanoes. Type B (29 Volcanoes), last erupted before $1600 \mathrm{AD}$ and show evidence of volcanic activity, such as fumaroles or solfatara. Type C (21 volcanoes), do not have any record of historic eruptions, but show fumarole and or sofatara activity. In 2015 (October), there were 18 volcanoes with activity above normal levels, 2 of those were in level 3 (Watch) and 1 in level 4 (Warning).

In hazard mitigation, there are 3 stages; pre-disaster, syn-disaster, and post disaster.
According to Law no 24 (2007) of the Republic Indonesia concerning Disaster Mitigation, efforts of mitigation shall be emphasized in pre-disaster activity programs, such as capacity building to prepare community awareness. Communication with the public is an important part of developing community preparedness in volcanic hazard zones. Our experience in Indonesia shows that disaster mitigation can only be achieved successfully if preparedness is carried out at the community level. During this process, participatory action to empower people is the key to people taking action during crisis according to their preparedness (e.g., Paton and Johnston 2001; Ronan and Johnson 2005).

This paper highlights the process of participatory management of crises and empowerment of responsible media to fill communication gaps between scientist and managers on one side and communities on the other side.

Below we describe methods used in Indonesia and lessons learned in seeking optimal preparedness.

\section{Disaster Mitigation in Indonesia}

In Indonesia, implementation for disaster mitigation is coordinated by the National Disaster Management Agency (BNPB) and by Provincial and Regional Disaster Management Agencies (BPBD), who are responsible for managing within their domains. The institution responsible 


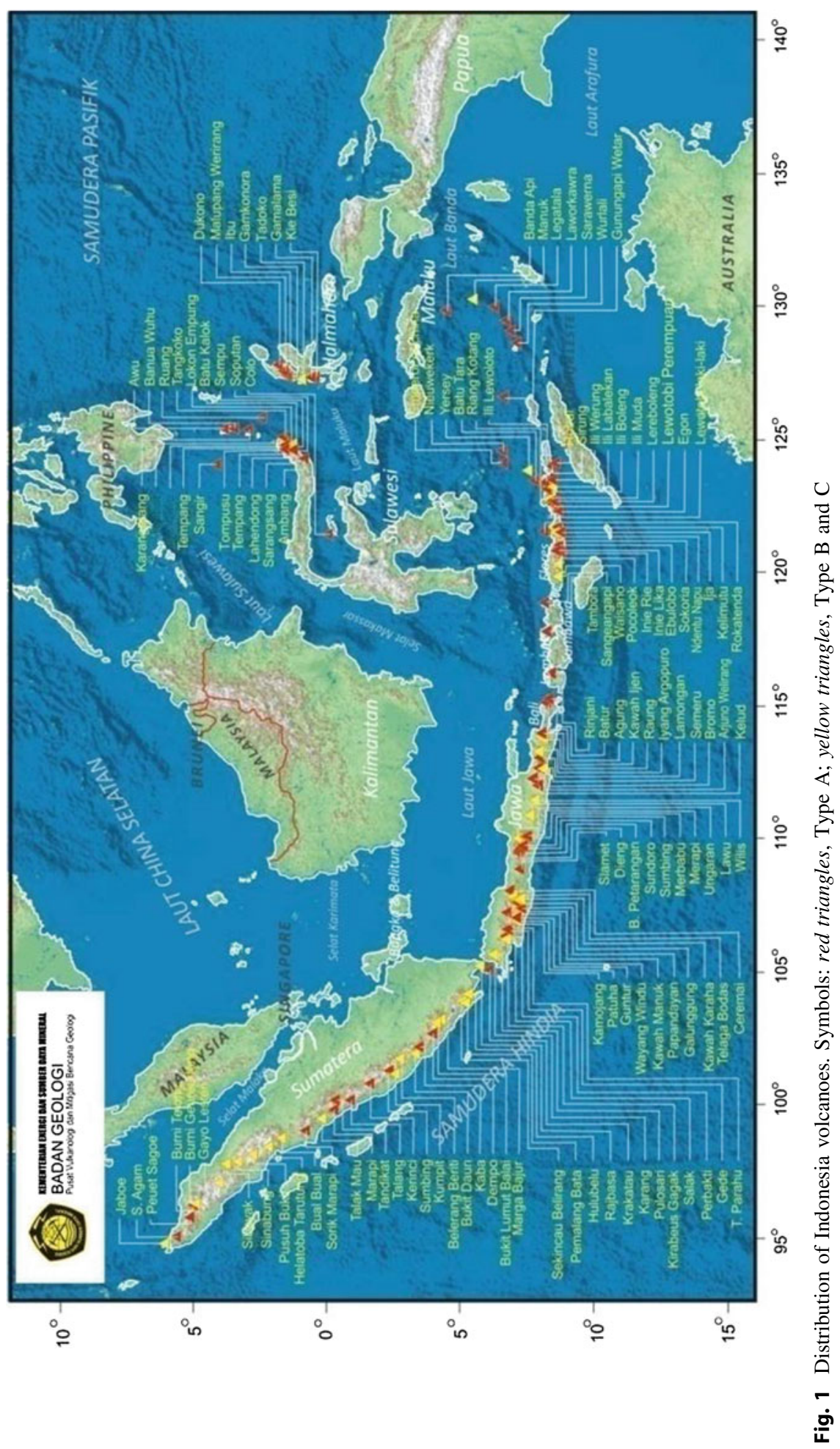


Table 1 Volcano activity in Indonesia

\begin{tabular}{l|l}
\hline Level of volcanic activity in Indonesia \\
\hline Normal level & $\begin{array}{l}\text { Visual observations and instrumental records show normal fluctuations, but no change of } \\
\text { activity } \\
\text { Hazards in the form of poisonous gas may take place near vents according to the volcano's } \\
\text { characteristic activity }\end{array}$ \\
\hline $\begin{array}{l}\text { Waspada level } \\
\text { (advisory) }\end{array}$ & $\begin{array}{l}\text { According to visual observations and instrumental records there are indications of increasing } \\
\text { of volcanic activity }\end{array}$ \\
\hline Siaga level (watch) & $\begin{array}{l}\text { According to visual observation and instrumental records there are prominent indications of } \\
\text { increasing volcanic activity. Eruptions may take place but do not threaten settlements and/or } \\
\text { activities of communities near the volcano. }\end{array}$ \\
\hline $\begin{array}{l}\text { Awas level } \\
\text { (warning) }\end{array}$ & $\begin{array}{l}\text { According to visual observations and instrumental records, there are significant indications } \\
\text { of volcanic activity, which are followed eruptions and potentially threaten settlements and or } \\
\text { community activities around the volcano }\end{array}$ \\
\hline
\end{tabular}

for overall volcano hazard mitigation is the Center for Volcanology and Geological Hazard Mitigation (CVGHM), which uses 4 alert levels (Table 1) to communicate hazards and recommend actions to be taken by the Disaster Management agencies. The alert levels are: Normal, Advisory (Waspada), Watch (Siaga) and Warning (Awas). Characteristics of volcanic activity are defined for each alert level and specific activities of mitigation are linked to the alert levels. For Normal, Advisory and Watch levels these activities include socialization, preparation of contingency plans, simulations (e.g., table top exercises), and evacuation drills. When the highest alert level (Warning) is declared, evacuation of people in a specified threatened area is recommended by CVGHM, and the local authorities take the action to evacuate the people.

During levels Watch and Warning, communication to the public and amongst stakeholders becomes intense and frequent. Communication is accomplished in various ways, including telephone (mobile and land-lines), text messaging, fax, television, radio and radio streaming; the latter is arranged by communities and typically utilizes hand-held citizens-band radios for streaming information.

In order to understand the information and disaster mitigation processes, socialization and simulations (table top exercises, "TTX") are conducted with local disaster mitigation agencies and selected community members (see Fig. 2). Simulations are implemented according to community contingency plans for threatened areas. These exercises help stakeholders and community members understand volcanic hazard information and what to do to respond according to their contingency plans. A wide range of stakeholders are involved, including both local national authorities, such as representatives from agencies involved in public works, social, health, energy and mineral resources (parent agency for CVGHM), and transportation, as well as the Central Bureau of Statistics, Non-Governmental Agencies (e.g., Red Cross), and volunteers.

\section{Gaps in Communication}

Understanding information flow as a part of early warning systems is essential for dissemination of hazard information to the public. There are a number of factors that can hamper the process of communication, i.e.: culture and language, hazard perception, mandates and policy. According to Damen (1987), culture may be defined as learned and shared human patterns or models for living. Therefore, culture relates to mankind's adaptive mechanisms and includes local beliefs, religion, language, social habits and communication.

In hazard mitigation, a cultural approach is used to improve the capacity of a community to cope with disaster. Donovan (2009) noted that social and economic factors should be considered, such as during the Merapi crisis of 2006. In Indonesia, the culture of a community largely affects 


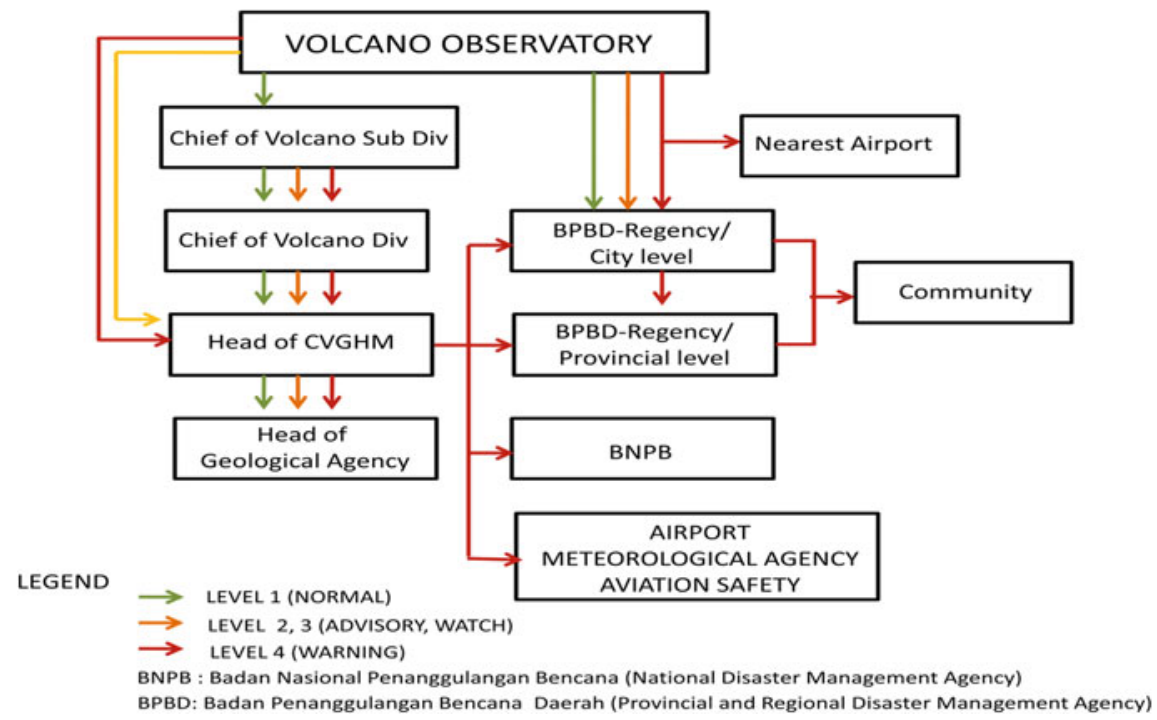

Fig. 2 Information flow during volcanic activity. This diagram illustrates how information flows from CVGHM to Disaster Management Agencies and other related institutions

individuals' perception of hazards. This perception relates strongly to local beliefs, which are typically associated with the community members' experiences during previous eruptions and with physical barriers or obstructions between them and the volcano (Lavigne et al. 2008). An example of a change in physical barriers was evident during the 2006 eruption of Merapi. People on the southern flank of the volcano had long believed that the Gegerbuaya ridge protected them, as it had for decades. The Gegerbuaya was a steep ridge near the summit of Merapi that protected much of the southern flank, as it directed pyroclastic flows to the southwest. However, during the 2006 eruption, the Gegerbuaya was eroded and subsequent pyroclastic flows and surges in 2006 and during the large "100-year" eruption in 2010 had a profound impact not just to the southwest, but also on the southern flank. Unfortunately, the perception of protection of the southern flank persisted long after the "protector" (the Gegerbuaya) had ceased to exist. Consequently, it was important to overcome this long-held misperception through community education during the 2006-2010 time interval.

In most cases, communication from scientists and disaster managers to the public is complicated by uncertainty involved in eruption forecasting and by limitations in understanding by public authorities. This may lead to uncertainty in decision-making and accordingly, in public mitigation actions (Morchio 1993). Consequently, effective two-way communication between parties is important. Simple language to deliver hazard information, supported by a cultural approach is one of the solutions.

Indonesia is a nation of diverse cultures and religions, and as noted by Chester (2005) in such environments religious and community leaders have important roles in disaster management. This is the case in certain areas of Indonesia, where communication between government scientists or disaster managers and society is most effective when done through religious or community leaders. For example, hazard communication during the ongoing Sinabung volcanic crisis in Sumatra has been more effective through the local religion leaders; whereas, communication through other community leaders was effective during recent crises at Merapi and Kelud volcanoes in Java.

The manner of communication, including culturally sensitive approaches, use of local languages, and appropriate means of delivery of 
information is critical. Indonesia has hundreds of local languages, although Bahasa Indonesia ("language of Indonesia") is the common denominator for hazard communication and in general socialization of hazard information is carried out in Indonesian. However in some places, local languages are still needed for communication and understanding and to be effective. In order to enhance communication and to improve hazard mitigation in this diverse linguistic and cultural nation, CVGHM operates 68 local observatories, staffed by observers from nearby communities who speak local languages.

\subsection{Hazard Perception}

The response of disaster mitigation agencies and communities to anticipate disaster depends on a common understanding of the hazards and an ability to take action during the event. Differences in hazard perception among emergency managers and scientists can lead to different and sometimes confusing and dangerous response actions. Our experience is that such differences may be caused by overlaps in mandate and authority, different levels of knowledge, errors in communication and coordination amongst stakeholders, and by ineffective communication between government authorities and communities. These issues are not unique to Indonesia. Qualitative and quantitative studies by Haynes et al. (2008a) of the factors controlling risk perception during the volcanic crisis on the Caribbean island of Montserrat show that difficulties in communication and understanding of uncertainties pertaining to volcanic risk led to confusion and social, economic and political forces resulted in distorted risk messages.

Hazard perceptions of local governments and communities are also influenced by their experiences during previous disasters. Communities from Kelud and Merapi have had far more experience in dealing with eruptions than the communities around Sinabung. The experience of those near Kelud and Merapi has allowed them to quickly understand the hazard information and respond appropriately during recent crises. In contrast, the communities near Sinabung (which had not erupted in hundreds of years) had less experience, and were thus less aware and less able to respond as effectively during the crisis. This example of a population that is not experienced in volcanic eruptions is by no means unique. For example, Solana et al. (2008) notes that even though local authorities are aware of the hazard at Vesuvius, there is still incomplete understanding among communities as to how to respond during a volcano crisis.

\subsection{Mandate and Policy}

As previously noted, the responsibility for coordination of disaster management in Indonesia lies with the National Disaster Management Agency (BNPB) and with the Provincial and Regional Disaster Management Agencies (BPBD). BNPB has the mandate to coordinate all the stakeholders and to manage the situation during crisis. Therefore, all reports regarding events are firstly delivered to this agency for action. BNPB also has authority to publish policies, guidelines and protocols related to preparedness, mitigation and emergencies regulation. While this is of great value at the national level, a lack of socialization and understanding of the regulation at the local level may result in less than optimum implementation.

Although specific mitigation actions, such as evacuations are carried out by local authorities and managed by BPBD, the overall mandate for the information that results in the mitigation of volcanic hazards in Indonesia is given to CVGHM. This institution is responsible for volcano monitoring, issuing alert levels, and providing recommendations for evacuation to BNPB, BPBD and local governments and for dissemination of hazards information. The protocol for determination of alert levels is established by CVGHM. Problems have arisen in cases when other institutions or individuals have intervened by issuing 
statements to the mass media, in some cases even causing panic among the public.

\section{Problems and Solutions in Communicating Hazards and Achieving Community Preparedness}

The aim of the dissemination of knowledge about hazards should be to create awareness among the threatened parties and we suggest that the biggest improvement in communicating hazards in Indonesia will come about through encouraging actors to behave and act equally and in harmony. However, in implementation, we find that there is often a disparity between hazard mitigation actors. Frequently, hazard mitigation institutions attempt to impose their role at levels higher than that of the community. In these cases, key roles of assessment and participatory learning may be considered inappropriate and therefore may not be used. In such cases, dissemination of information tends to be carried out from the top down and centralized, often delaying transmission of critical information and contributing to misunderstanding at the local level. Occasionally, the source of knowledge depends on a single person or group. In other cases during crisis, many groups of people may get involved in dissemination of information without proper knowledge and without adequate coordination with the institution responsible for socialization. We have found that the best result in improving community preparedness is achieved when the style and mode of communication between actors changes gradually. An informal approach is a key factor in good communication, and we find that such an informal mode is an effective means to transfer knowledge through participatory activities during the quiet times between volcanic crises.

\subsection{The Role of Media}

Involvement of media or mass communication is important to improve public knowledge and response capacity. Access to public media is very much a part of daily public life in Indonesia and at all levels of society. Consequently, it is an effective means for both long-term education and for short-term communication of hazard information. To transfer hazard information to the public several mass media methods are used, namely direct communication through television programs, interviews and articles in newspapers, and webpages. In addition, socialization programs are provided by CVGHM to target priority audiences, utilizing workshops, seminars, exhibitions and formal or informal discussions with the public in the areas of concern.

To enhance the effectiveness of mass media communication, workshops with reporters and scientists on translation of technical data into public language have been carried out. Potential problems include the reporters and the media companies' own interests in how they deliver hazard messages. CVGHM recognizes this need and works with reporters to keep the message appropriate to the scale of the hazards and to make sure that critical public safety messages are effectively communicated. In addition, we recognize value of involving media in observation of capacity building of communities before, during and after disasters. Although the media is typically less attracted in pre-disaster activities, our involvement with news reporters during crises and following disasters helps increase interest in public-interest and capacity-building stories about pre-disaster activities, which might otherwise be neglected by the media.

\subsection{Building Trust}

To build trust between scientist and communities, equity in level of communication is important, in addition to understanding of local culture, local language and people's character. Sharing information to identify problems will also encourage people be more involved in hazard mitigation. Various targets and conditions of communities during the capacity building process stimulate scientists to be flexible and modify procedures and understanding of hazards. This may include equating perception and 


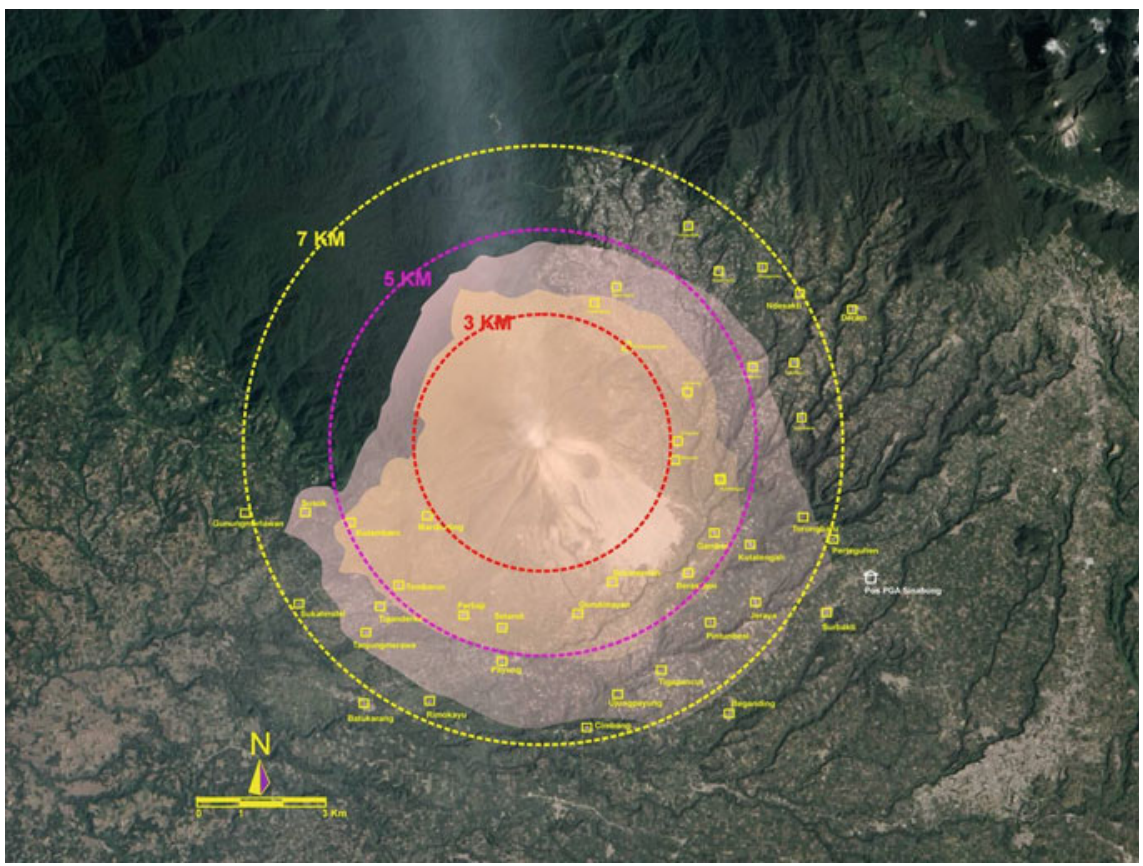

Fig. 3 Map showing direction of pyroclastic flows of Sinabung volcano on 1 February 2014 (black arrow) and $5 \mathrm{~km}$ exclusion zone (magenta dashed circle)

terminology to other more commonly understood threats to communities.

Here we describe how pre-established trust of communities in government (scientists and disaster managers) during the volcano crisis of February 2014 at Kelud resulted in a timely and efficient evacuation. People obtained and distributed information to others by community radio, text messaging and community gatherings. The CVGHM observatory post was one of the main sources of information. New local community leaders emerged from a local disaster preparedness group known as Wajib Latih (Indonesian for "compulsory training"; a group defined in more detail below). Such leaders played an important role in communicating hazard information during the Kelud crisis. The Chief of the District of Ngancar was involved in the distribution of information through radio briefings with the help of local leaders and members of the communities. During the crises, the communities of Kelud were also involved in keeping the public away from exclusion zones.
This case illustrates the independency of communities to take action, and it represents a bottom-up process in mitigation.

In contrast, a low capacity and experience of Sinabung communities resulted in inconsistent responses, such as repeated requests for confirmation of hazard information, attempts to negotiate before taking action, and less consideration in taking risks. A tragic example took place during the Sinabung eruption on 1 February 2014, which resulted in 17 fatalities. As a consequence of ineffective understanding of the risk, these people entered the $5 \mathrm{~km}$ exclusion zone (Fig. 3) and were killed by a pyroclastic surge.

Improvements in the capacity of Sinabung communities have resulted from the efforts of staff members of CVGHM conducting socialization work. These improvements are clearly a result of increasing trust of community leaders in the relevant communicator. Such individual trust building is an important way to improve volcanic risk communication (Haynes et al. 2008b). 


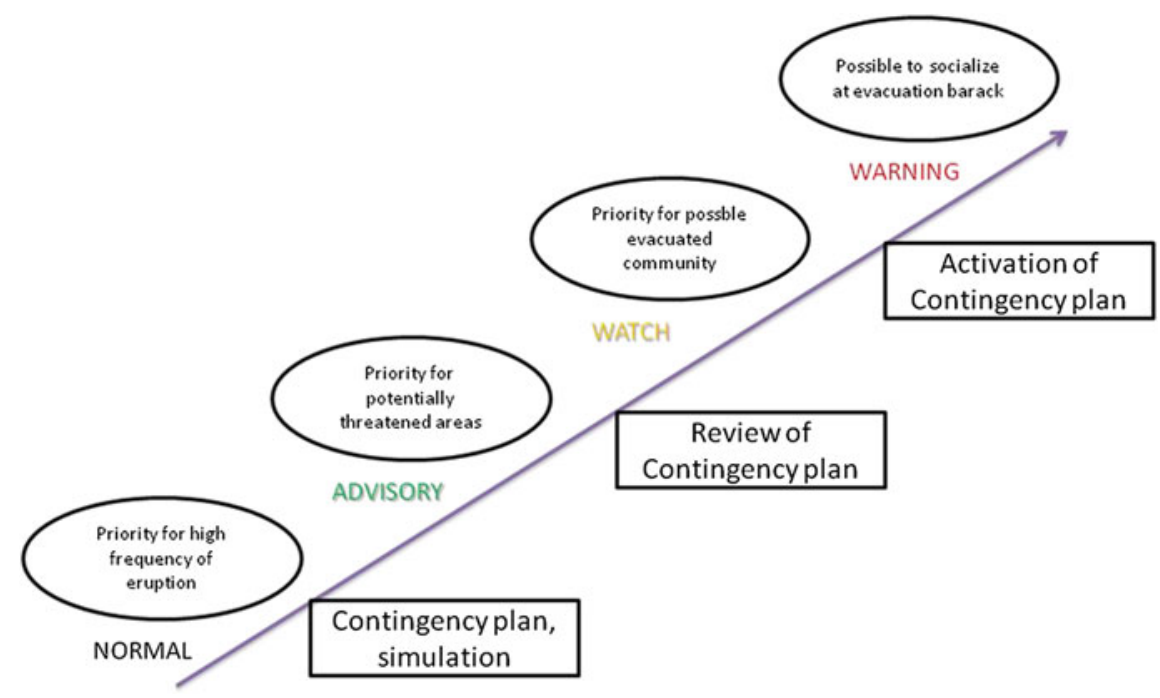

Fig. 4 Capacity building in communities and its implementation during volcano eruption according to alert level

Indonesia has a unique involvement of scientists in mitigation actions related to volcanic eruptions. As a mandate holder, CVGHM is responsible not only for monitoring and volcano hazard evaluation, but also for mitigation of volcanic hazards, as alert levels are directly tied to mitigation actions and areas recommended for evacuation are specified in formal CVGHM notifications. Scientists and decision makers who issue volcano alert levels are in the same institution. Scientists from different institutions may provide input based on research but do not to issue alert levels. Further, decision makers communicate directly with disaster managers, such as BNPB and BPBD and provide specific recommendations regarding mitigation actions. BNPB and BPBD arrange, prepare, and through local authorities enact mitigation plans.

\section{Steps of Knowledge Transfer and Communication}

In general, there are several steps in delivering information that we use in Indonesia, namely socialization, preparation of contingency plan documents, simulation and evacuation drills.

\subsection{Socialization}

Socialization is dissemination of hazard information to people at risk. In Indonesia, the level of volcano activity and priority of socialization by CVGHM changes at different alert levels (Fig. 4). At the Normal level, socialization is given to people living close to volcanoes that experience a high frequency of eruptions. At the Advisory level, socialization is carried out with priority to people in the area potentially threatened by hazards. At Watch level, it is carried out in area which will likely be evacuated in the case of a Warning level alert. At the Warning level, additional socialization is conducted in evacuation camps or barracks, if it is needed.

In hazard zones where there is a high frequency of volcanic eruptions, continuity of hazard information is important to maintain awareness of threatened communities. A model of participatory training is most appropriate in these situations. This model aims to implement "training of the trainer" or compulsory training ("Wajib Latih," in the language of Indonesia). Wajib Latih represents the lowest social level of disaster management and mitigation planning. It is a disaster management learning activity that is undertaken to bring 

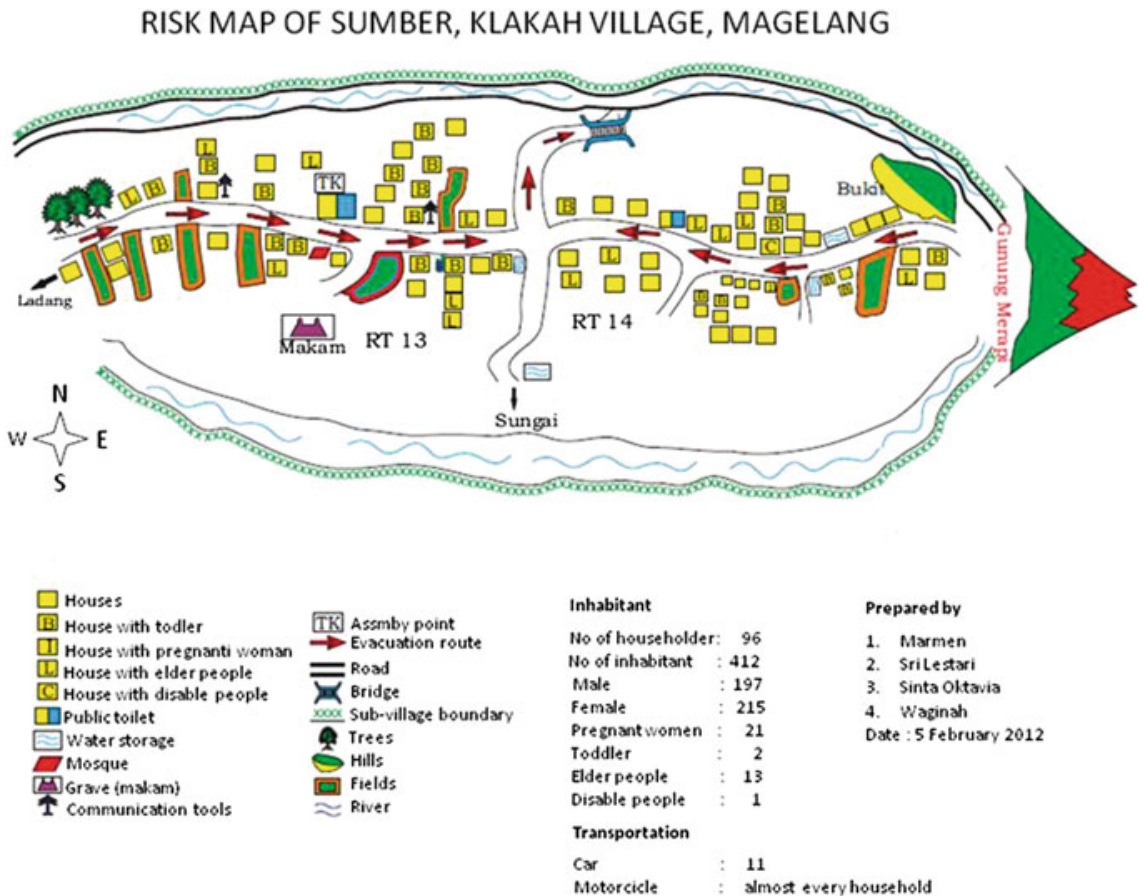

Fig. 5 Village risk map shows total number of inhabitants, resources, locations of vulnerable groups and infrastructure for evacuation

together the instructors, local stakeholders and community leaders. Most activities are conducted by CVGHM and result in the creation of a new local leader. From our experience, the creation and establishment of such a local leader plays an important role in effective community evacuation. Through Wajib Latih, information is shared within communities and by members of communities. In this activity, the group has the task to formulate a contingency plan and SOP of evacuation, including making village risk maps (Fig. 5). Each member of the group is given a specific responsibility and as a result, each acts as a leader of their own task. Because the plan is created by the community itself, it is easily understood and effectively utilized by the community.

The Wajib Latih requires a common perception between government and the community in order to create a sharing environment to find solutions. However, even with this community-based process, this condition is difficult to achieve as even in areas near a volcano, hazard perception may vary from sector to sector.
To a significant degree the success of the method depends on the experience of those involved in dealing with the hazard directly and repeatedly.

\subsection{Contingency Plan}

According to UNISDR (2009) "contingency planning is a management process that analyses specific potential events or emerging situations that might threaten society or the environment and establishes arrangements in advance to enable timely, effective and appropriate responses to such events and situations".

By Public Law in Indonesia, contingency plans include scenarios and goals, establishment of technical and managerial actions, as well as response plans for mobilization of mutually agreed stakeholders (Government of Indonesia 2007). The formulation of a contingency plan is carried out in two ways, namely community-based and stakeholder-based. Contingency plans are prepared by village (through Wajib Latih groups), 
and also at regency and national levels (stakeholder-based). At Merapi and Kelud, both of these two approaches were carried out. In preparation of the contingency plans, many stakeholders are involved. Stakeholders involved in Wajib Latih groups include CVGHM, local authorities at village level, community health centers, community preparedness groups, volunteers, and representative community members and leaders. Stakeholder-based contingency plans involve CVGHM, local authorities at regency and provincial levels, local health, public works, social, communication and information, and transportation agencies, community preparedness groups, volunteers, Red Cross/Red Crescent and search and rescue units. During the process of formulating contingency plans, the input of stakeholders is needed to define their appropriate roles. Formulation of the contingency plan includes identification of hazard, threat, and vulnerability, as well as a determination of possible disaster impacts, risk reduction measures, readiness and response mechanisms, and a distribution of tasks, mandates and available resources (Government of Indonesia 2008). Besides providing the contingency plan document and SOP for evacuation, the process also improves communication and coordination of hazard perception amongst stakeholders and community leaders.

The Wajib Latih process is similar to Participatory Rural Appraisal (PRA) methods implemented in the Solomon Islands (Cronin et al. 2004a, b), which involves stakeholders from communities and government to encourage community-based planning. Wajib Latih and PRA emphasize the important of dialogue among stakeholders to integrate various aspects, both social and physical to derive risk assessment and mitigation plans.

Increased capacity of a community requires not just knowledge of the hazard but also effective communication and coordination, in which those responsible for crisis management understand the policy, guidelines and standard operating procedures of the entire process. Therefore, in the preparation of contingency plans it is important to document and empower hazard mitigation institutions (stakeholders) and the community at risk. Contingency planning also requires understanding of the mandates of each institution and the distribution and coordination of authorities. During contingency planning and through simulation of the plans, needs and gaps are identified and addressed with solutions that will be effective during future crises. Contingency plans are not only useful to identify hazards and vulnerabilities and to enhance understanding of evacuation procedures, but the preparation of these plans also builds a critical communication network and coordination amongst stakeholders, community leaders and members of villages.

As previously noted, preparation of these plans takes place during Normal or Advisory alert levels. In the Watch level, a review of contingency plan is carried out in order to update all data before a real disaster and the contingency plan is changed to an operation plan. At this time and at higher governmental levels (regency/provincial and national levels) an Incident Commander is appointed. The operational plan is then used by the Incident Commander and all stakeholders to guide the response, typically an evacuation (Fig. 4). Activities of communities in each Alert level are shown in Table 2.

\subsection{Simulation (Table Top Exercises)}

Table top exercises are designed to test the ability of disaster mitigation officials to respond. In this case, the exercise also aims to test and review the procedures set out in the contingency plan. The exercise involves key persons from the various sectors as described in the contingency plan. As used by CVGHM, the nature of the exercise is informal, such that participants may improve the scenarios, share information and experiences, and overall provide input to improve the plan.

\subsection{Evacuation Drills}

Drills are used to practice evacuations involving communities and all stakeholders. These exercises are carried out in the field, involve 
Table 2 Volcano alert levels and community preparedness taken from the Indonesia national standard training guideline for community preparedness to anticipate hazards of volcanic eruption (in press)

\begin{tabular}{|c|c|}
\hline Alert level & Activity of community \\
\hline Normal (normal, level 1) & $\begin{array}{l}\text { 1. Socialization of volcanic hazard map } \\
\text { 2. Understanding of character of volcano hazards } \\
\text { 3. Community understanding regarding their settlement within volcanic hazard map } \\
\text { 4. Census of inhabitants within hazard zones } \\
\text { 5. Inventory of resources within hazard zones } \\
\text { 6. Formulation of SOP } \\
\text { 7. Preparation of sign and evacuation route } \\
\text { 8. Simulation }\end{array}$ \\
\hline Advisory (Waspada, level 2) & $\begin{array}{l}\text { 1. Dissemination of increasing alert level } \\
\text { 2. Updating census of inhabitants } \\
\text { 3. Updating of vulnerability of inhabitants within hazard zones } \\
\text { 4. Intensification of inventory of resources within hazard zones } \\
\text { 5. Preparation of equipment and communication system } \\
\text { 6. Preparation of evacuation plan } \\
\text { 7. Preparation of transportation for evacuation } \\
\text { 8. Preparation of evacuation barracks } \\
\text { 9. Preparation of logistics } \\
\text { 10. Explanation to community } \\
\text { 11. Grouping of communities }\end{array}$ \\
\hline Watch (Siaga, level 3) & $\begin{array}{l}\text { 1. Dissemination of increased alert level } \\
\text { 2. Sign of alert is ready to be operated } \\
\text { 3. Transportation for evacuation is ready to be operated } \\
\text { 4. Evacuation barracks are ready to be operated } \\
\text { 5. Logistics are ready to be operated } \\
\text { 6. Security is ready to be operated } \\
\text { 7. SOP is ready to be operated } \\
\text { 8. Equipment and communication system is activated } \\
\text { 9. Determination of the emergency response command }\end{array}$ \\
\hline Warning (Awas, level 4) & $\begin{array}{l}\text { 1. Dissemination of increased alert level } \\
\text { 2. Warning signals are sounded } \\
\text { 3. Evacuation order from Incident Commander is executed } \\
\text { 4. Activation of SOP } \\
\text { 5. Evacuation } \\
\text { 6. Activation of evacuation barracks } \\
\text { 7. Activation of logistics } \\
\text { 8. Activation of security } \\
\text { 9. Activation of crisis center }\end{array}$ \\
\hline
\end{tabular}

Alert levels are given in English and Indonesian (in parentheses)

vulnerable people and mobilize resources and communities according to scenarios from the contingency plan. Our experience is that review of the contingency plan during evacuation drills substantially improves the plan. For example, risks related to the route of evacuation, location and facilities at evacuation camps or barracks and modes of transportation are all commonly addressed and solutions found.

\subsection{Leadership}

In disaster management, the role of leadership is important, both for decision makers and local leaders. As previously noted, during the capacity building process of institutions and communities, often a new leader emerges. Such a leader can mobilize disaster management agencies and communities to take action according their 
capacity and capability to anticipate disaster. The new leader is typically most effective during the evacuation process. In our experience and across a wide variety of Indonesian cultures, we find that a trusted community leader is patient, open-minded, caring, flexible, and a good communicator. Such a leader also has great endurance. The function of a leader in the community is to serve as a role model and initiator; one who encourages people to take proper action according to their capability.

\section{Conclusion}

Communicating hazard information is a time consuming process, as the interaction between community (social) and scientists (physical perspectives) and disaster management agencies (policy and practice) requires equity in hazard perception. We find that informal approaches are keys to success. An informal nature of communication encourages people to share experience, knowledge and problems without regard to their background differences and is best accomplished through socialization using a participatory knowledge dissemination methods. These activities are carried out through discussion and sharing of experiences among actors, analyzing problems from different perspectives to find solutions, and involvement of various groups to maintain diversity and necessity. The main point of the activity is to identify underlying problems in hazard perception, cultural backgrounds and community characteristics and to harmonize the point of view of both hazard mitigation officials and communities. This is consistent with the conclusion of Howes and Minos-Minopoulos (2004), who pointed out the importance of public perception of hazard, risk and vulnerability in relation to public education programs and disaster management plans.

One of the factors to motivate communities to protect themselves from natural disasters is to encourage people to find out where and how to obtain hazard information and to conduct their own assessments that lead to appropriate actions. This can be achieved by empowerment of communities through participatory learning. Perry and Lindell (2008) proposed that there is correlation between responsibility for self-protection of the community that has had an experience of property damage and information seeking behavior related to protective action. We find this to be the case in Indonesia.

Both Merapi and Kelud communities are experienced the Wajib Latih process. The core activity of Wajib Latih groups is to encourage people to be capable to respond and take action appropriately during crisis. This behavior can be achieved through intensive training and involvement in the preparation of mitigation plans. The training also emphasizes the difference between evacuating and "being evacuated." The first case implies being prepared and actively participating and the second reflects being unprepared and passively participating. The evacuation processes at both Kelud and Merapi communities illustrates the value in preparedness. Even during the short-term crisis of the 2014 Kelud eruption (less than one day of warning), part of the community evacuated themselves before a recommendation for evacuation was issued (i.e., Warning level alert being issued). This condition represents independency of the community to anticipate and take action during a crisis according to their capacity and knowledge.

An important lesson from the experience of disaster mitigation in Indonesia is the necessity to maintain effective communication between scientists and those responsible for mitigation by respecting mandates and authorities for disaster management and by directly involving communities in hazard mitigation. Such effective communication and community involvement is supported by development of policy, strategy and mitigation plans by government which involves public participation.

Acknowledgements We would like to thank to the Director of Center for Volcanology and Geological Hazard Mitigation, Indonesia for providing chance to us to involve in many activities in pre-disaster and during crisis. We are also grateful to John Pallister of the USGS, for provide fruitful comments, and in the preparation and editing of the manuscript. 


\section{References}

Chester DK (2005) Theology and disaster studies: the need for dialogue. J Volcanol Geotherm Res 146:319-328

Cronin SJ, Gaylord DR, Charley D, Brent V, Alloway BV, Wallez S, Esau JW (2004a) Participatory methods of incorporating scientific with traditional knowledge for volcanic hazard management on Ambae Island, Vanuatu, Bulletin of Volcanology, vol 66, pp 652-668

Cronin SJ, Patterson MG, Taylor PW, Biliki R (2004b) Maximising multi-stakeholder participation in government and community volcanic hazard management programs: a case study from Savo, Solomon Islands. Nat Hazards 33:105-113

Damen L (1987) Culture learning: the fifth dimension in the language classroom, vol 11478. Addison Wesley Publishing Company

Dominey-Howes D, Minos-Minopoulos D (2004) Perception of hazard and Risk on Santorini. J Volcanol Geotherm Res 137:285-310

Donovan K (2009) Doing social volcanology: exploring volcanic culture in Indonesia. Area 42:117-126

Government of Indonesia (2007) Law of Republic Indonesia no 24, 2007 concerning disaster mitigation, published by the Government of Indonesia

Government of Indonesia (2008) Regulation of Head of National Disaster Management Agency No 4, published by the Government of Indonesia

Government of Indonesia (2010) Badan Pusat Statistik (Central Bureau of Statistics). http://www.bps.go.id/ tab_sub/view.php?tabel=1\&id_subyek=12

Government of Indonesia (2014) Indonesia National Disaster Management Agency, Rencana Nasional Penanggulangan Bencana 2015-2019 (National Disaster Mitigation Plan), published by the Government of Indonesia
Government of Indonesia (2015) Indonesia National Standard, Training guideline for community preparedness against hazards of volcanic eruption (Standar Nasional Indonesia, Panduan Pelatihan Kesiapsiagaan Masyarakat Terhadap Bahaya Erupsi Gunungapi), published by the Government of Indonesia (in press)

Haynes K, Barclay J, Pidgeon N (2008a) Whose reality counts? Factors affecting the perception of volcanic risk. J Volcanol Geotherm Res 172:259-272

Haynes K, Barclay J, Pidgeon N (2008b) The issue of trust and its influence on risk, communication during a volcanic crisis. Bull Volcanol 70:605-621

Lavigne F, de Coster B, Juvin N, Flohic F, Gailard JC, Texier P, Morin J, Sartohadi J (2008) People's behaviour in the face of volcanic hazard: perspective from Javanese communities, Indonesia. J Volcanol Geotherm Res 172:273-287

Morchio R (1993) The effect of the uncertainty in natural prediction on the user communities. In: Nemec J, Nigg JM, Siggardi F (eds) Prediction and perception of natural hazards. Kluwer, Dordrecht, pp 39-47

Paton D, Johnston D (2001) Disasters and communities: vulnerability, resilience and preparedness. Disaster Prev Manag Int J 10:270-277

Perry RW, Lindell MK (2008) Volcanic risk perception and adjustment in a multi-hazard environment. J Volcanol Geotherm Res 172:170-178

Ronan KR, Johnston DM (2005) Promoting community resilience in disasters; the role for schools, youth, and families. Springer, New York $213 \mathrm{pp}$

Solana MC, Kilburn CRJ, Rolandi G (2008) Communicating eruption and hazard forecasts on Vesuvius, Southern Italy. J Volcanol Geotherm Res 172: 308-314

UNISDR (2009) UNISDR terminology on disaster risk reduction. United Nations International Strategy for Disaster Reduction, Geneva
Open Access This chapter is licensed under the terms of the Creative Commons Attribution 4.0 International License (http://creativecommons.org/licenses/by/4.0/), which permits use, sharing, adaptation, distribution and reproduction in any medium or format, as long as you give appropriate credit to the original author(s) and the source, provide a link to the Creative Commons license and indicate if changes were made.
The images or other third party material in this chapter are included in the chapter's Creative Commons license, unless indicated otherwise in a credit line to the material. If material is not included in the chapter's Creative Commons license and your intended use is not permitted by statutory regulation or exceeds the permitted use, you will need to obtain permission directly from the copyright holder. 